\title{
NATURALEZA DEL DERECHO DE SUBROGACIÓN EN EL CONTRATO DE SEGURO Y SU RELACIÓN CON LA COTITULARIDAD DEL ASEGURADO Y ASEGURADOR FRENTE AL TERCERO RESPONSABLE*
}

\section{THE NATURE OF THE RIGHT TO SUBROGATION IN INSURANCE CONTRACTS AND ITS RELATION WITH THE INSURED AND THE INSURER CO-OWNERSHIP VIS-Á-VIS RESPONSIBLE THIRD PARTIES}

\author{
MATEO SÁNCHEZ GARCÍA $A^{* *}$ \\ Fecha de recepción: 30 de abril de 2018 \\ Fecha de aceptación 24 junio de 2018 \\ Disponible en línea: 15 de marzo de 2019
}

Para citar este artículo/To cite this article

Sánchez García, Mateo, Naturaleza del derecho de subrogación en el contrato de seguro y su relación con la cotitularidad del asegurado y asegurador frente al tercero responsable, 49 Rev.Ibero-Latinoam.Seguros, 15-53 (2018). https://doi. org/10.11144/Javeriana.ris49.ndsc

* Artículo de investigación.

** Abogado de la Universidad del Rosario, Magister en derecho contractual Universidad Autónoma de Madrid y Doctorado de la misma Universidad. Orcid: 0000-0003-4386-4469. Profesor Universidad Central de Colombia. Contacto: mattteooo@hotmail.com 


\section{RESUMEN}

El presente artículo pretende exponer de manera analítica y reflexiva la naturaleza del derecho de subrogación o llamado recupero del asegurador frente al tercero responsable del siniestro, así como sus implicaciones y naturaleza en la cotitularidad de derechos entre el asegurado y el asegurador frente al tercero responsable, y en especial frente al fenómeno de la insuficiencia del crédito o insolvencia parcial del tercero responsable, teniendo como marco normativo la ley y jurisprudencia española.

Palabras clave: Cotitularidad; contrato seguro; tercero responsable; subrogación. 


\begin{abstract}
This article exposes analytically and reflectively the nature of the right to subrogation in insurance. The implications and nature in the co-ownership visà-vis responsible third parties and especially in the face of the phenomenon of insufficient credit or partial insolvency of the third party responsible, having as a regulatory framework the Spanish law and jurisprudence.
\end{abstract}

Keywords: co-ownership, insurance contracts, responsible third parties, subrogation.

\title{
SUMARIO
}

INTRODUCCIÓN - 1. CUANTÍA DE LA PÉRDIDA Y CUANTÍA DE LA INDEMNIZACIÓN - 2. LA SUBROGACIÓN PARCIAL DEL ASEGURADOR - 3. INSUFICIENCIA DEL CRÉDITO FRENTE AL TERCERO RESPONSABLE EN CASO DE SUBROGACIÓN PARCIAL - 4. LA SUBROGACIÓN EN GENERAL Y SU RELACIÓN CON EL SEGURO - BIBLIOGRAFÍA. 



\section{INTRODUCCIÓN}

La acción subrogatoria, por parte del asegurado frente al tercero responsable surge, como un mecanismo jurídico para la recuperación del importe pagado por el asegurado como causa exclusiva del pago en el contrato de seguro, siendo este el principal requisito para su ejercicio. En caso contrario el asegurador se estaría beneficiando indebidamente de un monto que no le corresponde y que en teoría le correspondería exclusivamente al asegurado o sus beneficiarios. Dicho límite aparece claramente establecido en al artículo 43 en la LCS al afirmar que el asegurador podrá ejercitar los derechos y acciones del asegurado frente al tercero responsable "hasta el límite de la indemnización." Es claro entonces que la figura de la subrogación no se ha establecido en el sistema jurídico como una figura de carácter especulativo, sino como una de protección común de orden público tanto para el asegurador como para el asegurado, por ello su naturaleza sería diametralmente opuesta a otras figuras como la cesión de crédito o la cesión de contrato.

A la vez que el asegurado debe realizar efectivamente el pago ${ }^{1}$, el asegurador tendrá su parte en la ecuación; en efecto una vez recibida la indemnización por parte del asegurador, este deberá propiciar porque el asegurador reclame lo pagado, y no podrá como es lógico intentar reclamar frente al tercero dicha suma, puesto que el daño ya le ha sido resarcido por el seguro, de tal manera que el asegurado carecerá de interés y por ello legitimación en la causa para reclamar del tercero responsable suma alguna.

Hasta este momento la cuantía y el límite a la subrogación es perfectamente determinable, y será inherente a la proporcionalidad de la ecuación que el asegurado pueda ejercer su derecho al recobro, derecho protegido con respecto al asegurado por el artículo 43, el cual dispone que el asegurado "será responsable de los perjuicios que, con sus actos u

1 La jurisprudencia y la doctrina es enfática al reiterar que el límite del derecho de subrogación del asegurado, se encuentra determinado por el monto efectivamente pagado. A manera de ejemplo podemos citar las siguientes: Audiencia provincial de Barcelona, sentencia de 7 de septiembre de 1998, AC núm. 9005. Audiencia provincial de Madrid, sentencia de 15 de julio de 1998 AC núm. 1802. Doctrina: M.A. Clarke, the low of insurance contracts, 6 ed; Londres, 2009 P. 1028, TATO PLAZA (2003) la subrogación del asegurador en la ley de contrato de seguro, ed Tirant lo Blanch, 2002, pág. 153 . 
omisiones, pueda causar al asegurador en sus derechos a subrogarse, este principio tiene como finalidad asegurar el restablecimiento de la ecuación económica, una vez ha sucedido el siniestro. En efecto en los seguros de daño el siniestro provoca daños en el patrimonio del asegurado, y al producirse la subrogación afectará a su vez el patrimonio del asegurador. De tal manera que cuando existe un siniestro, el ordenamiento jurídico propende por restablecer el equilibrio en los patrimonios afectados, sustituyendo las pérdidas patrimoniales sufridas por derechos de crédito tanto del asegurado contra el tercero responsable o ya sea del asegurador contra este último. La regla plasmada en el segundo párrafo del artículo 43 se concreta principalmente en dos tipos de protecciones a saber, una de carácter general de no perjudicar el crédito²; y una específica de abstenerse de aquellas actuaciones que implique la desaparición del mismo como puede ser el pago, la remisión o la transacción. Tal es el caso en el que el asegurado se adelanta al cobro frente al tercero responsable del siniestro. Es claro que en estos últimos casos la finalidad de la norma sería la de evitar el enriquecimiento injustificado por el posible doble pago de la indemnización, y no como se podría pensar el garantizar al asegurador, el crédito que le correspondía al asegurado. Es claro que el principal interés de la empresa aseguradora no es la de quedar en la posición del asegurado considerando una mejor posición de la que estaba, más aun cuando la figura no está instituida como un mecanismo especulativo, y su límite está determinado por lo pagado, por el contrario el interés como ya lo dijimos sería principalmente el reembolso efectivamente pagado por el asegurador, se ha considerado por parte de la doctrina que el segundo párrafo del artículo 43 del LCS, se trata de un deber para el asegurado o una carga para el mismo ${ }^{\underline{3}}$, añadiendo que es el mecanismo jurídico de compensación económica, que resulta como consecuencia de la injerencia en la responsabilidad del tercero causante del daño en el contrato de seguro cuando el asegurador ha hecho efectivo el pago parcial o total del daño sufrido al asegurado. En efecto tal como lo establece el artículo 26 de la ley de seguro, que especifica con total claridad que el seguro no puede ser objeto de enriquecimiento injusto,

2 Estas pueden consistir en accione u omisiones y pueden ser muy diversas, por ello los autores los clasifican teniendo en cuenta varios criterios, tales como: el no reconocimiento por parte del asegurado de la no responsabilidad del tercero responsa, o el reconocimiento de su propia, o la inobservancia de los plazos de prescripción etc. Al respecto se puede consultar: J GARRIGUES (1973) contrato de seguro terrestre, p.202. 
de tal manera que el seguro no tolera ni concibe el enriquecimiento que por demás es el fundamento del principio indemnitario.

Por tanto, será imposible que la indemnización recibida por el asegurado sea superior al efectivo daño o lesión sufrida. Este límite comprenderá además dos parámetros, por un lado, la suma pactada es decir la suma convencional que se estipuló en el contrato de seguro, y de otra el límite legal, que es la cuantía del daño realmente sufrido en el patrimonio del asegurado, por tanto, este no podrá a no ser que medie cláusulas de asignación de valor exigir una indemnización superior al daño, ni mucho menos recibirla. De la misma manera el límite al pago del asegurador estará determinado por esta cantidad sin que le sea permitido un pago mayor; pero que será parcial si parte del pago por ejemplo es efectuado anticipadamente por el tercero responsable, en todo caso solo le será permitido reclamar a la aseguradora lo efectivamente pagado, esto en virtud del principio de equivalencia referenciado, pero este principio permite pacto modificatorio, en efecto existen tipos de pólizas, y clausulados que toleran ciertos umbrales de infraseguro, seguros a valor presente, $o$ incluso el grado de decisión que tiene la asegurador a oponerse a esas exigencias que sobrepasen el límite de la subrogación, e incluso oponerse a la causa resarcitoria.

\section{CUANTÍA DE LA PÉRDIDA Y CUANTÍA DE LA INDEMNIZACIÓN}

Reconociendo el carácter indemnizatorio que tiene el seguro, lo ideal sería que el valor asegurado sea equivalente al valor de la del interés asegurado para que en la eventualidad del siniestro, total o parcial la indemnización pueda ser igual al monto de la perdida lo cual cumpliría en su totalidad con su función teleológica que no sería otra que la satisfacción del pleno interés del asegurado, sin embargo esta situación de correspondencia entre uno y otro, no se da y tampoco es exigida por el legislador y son diversos los factores que contribuyen a que en la mayoría de situaciones el asegurado solamente reciba una reparación parcial y deba soportar una parte de la perdida. Puede ocurrir que se haya pactado 
una franquicia o un deducible, o que la póliza contenga cláusulas que impongan al asegurado el deber de soportar una cuota en el riesgo o pérdida o afrontar incluso una parte en el daño so pena de la resolución del mismo, en caso de la celebración de otro contrato que asuma la porción del daño faltante.

En términos más o menos similares, se pacta un deducible y coetáneamente con un mínimo, lo que significa que la aseguradora en todo caso no indemnizará en forma alguna ese valor base en la perdida, y en todo caso al determinar la cuantía de la indemnización, descontará el valor del deducible, como es lógico la compañía no aplicará franquicia y deducible al mismo tiempo y optará por la que represente un mayor valor dependiendo como es lógico de la cuantía de la perdida. Estas condiciones en el seguro no solo traslada parte del monto de la indemnización a favor de la aseguradora, sino que exige que asegurado, sea cuidadoso en la vigilancia y conservación de la cosa o cosas aseguradas y evite en lo posible la ocurrencia del riesgo es claro que así no sea pactada la franquicia o el deducible las partes deben ser diligentes, no solo porque así lo exijan los principios generales de los contratos, sino porque el contrato de seguros esta regentado de manera especial por el principio de buena fe. En efecto si el asegurado sabe que en caso de siniestro deberá asumir una parte del daño empleará un mayor cuidado de las cosas a las que están vinculadas el interés objeto del contrato, sin que haya incentivo para que provoque el siniestro. Otro de los efectos será el excluir las pequeñas reclamaciones evitando así los costos administrativos que dichos trámites les ocasionarían.

De la misma manera ya sea consciente o inconscientemente el tomador indica como valor asegurado una suma inferior al valor real del interés asegurado se presenta la condición del infraseguro, y por lo tanto si se da el siniestro total la indemnización será inferior al monto del daño y tendrá el asegurado que asumir la parte restante de la perdida, o a lo sumo siendo el daño parcial, y la compañía aseguradora advierte tal condición aplicará la regla proporcional, supuesto que se da cuando la suma asegurada es inferior al valor del interés en el momento de la producción del siniestro a esta condición se refiere el artículo 30 de la ley de contrato de seguro según el cual: "Si en el momento de la producción del siniestro la suma asegurada es inferior al valor del interés, el asegurador indemnizará el 
daño causado en la misma proporción en la que aquélla cubre el interés asegurado. Las partes, de común acuerdo, podrán excluir en la póliza, o con posterioridad a la celebración del contrato, la aplicación de la regla proporcional prevista en el párrafo anterior." El infraseguro enunciado en esta norma es el infraseguro final, pero también, podría ser inicial, sucesivo, voluntario o involuntario. Si el daño fuera total, la prestación del asegurador equivaldría a la suma asegurada, ya que el artículo 27 de la ley de contrato de seguro establece: "La suma asegurada representa el límite máximo de la indemnización a pagar por el asegurador en cada siniestro". De tal manera que, si el daño es parcial, se aplicará la regla proporcional enunciada en el artículo 30 de dicha Ley, en cuya virtud el asegurador indemnizará el daño causado en la misma proporción en que la suma asegurada cubra el interés asegurado. O dicho en otras palabras el asegurador solo ha de indemnizar el daño a prorrata entre la parte que esté asegurada y la que no lo esté. ${ }^{4}$ Con lo cual el infraseguro podría conducir a que en un determinado caso la indemnización resulte bastante inferior, a la cuantía del daño.

Suele fundamentarse la aplicación de la regla proporcional en la falta de proporción entre la indemnización y prima, al ser esta última insuficiente con respecto al interés asegurado ${ }^{5}$. Al respecto la doctrina ha justificado la regla proporcional, en la necesidad de que exista una perfecta armonía entre suma asegurada e interés asegurado, con sus efectos en caso de siniestro que pudiera ser favorable para el asegurado, ya que le será reintegrado un valor sustitutivo más real. Agregando que el asegurado tendrá la ventaja de reponer su daño patrimonial directamente del asegurador, con el agregado que supondría su realización de manera más ágil que si fuese directamente ante el tercero responsable, siendo el equivalente más adecuado, teniendo en cuenta el hecho de que el tomador ha pagado una prima insuficiente en relación a la totalidad del riesgo ${ }^{6}$.

4 Al respecto, se puede confrontar: VERDERA, TUELLS y OTROS (1982) Comentarios a la Ley de Contrato de Seguro, Vol. I, pp. 597-627. DÍAZ MORENO, Alberto: La disciplina de la póliza estimada en la Ley de Contrato de Seguro, Cuadernos Civitas, Thomson Civitas, Madrid, 2008, 1ª . Edición.

5 Al respecto, se puede confrontar: VERDERA TUELLS y OTROS (1982) Comentarios a la Ley de Contrato de Seguro, Vol. I, pp. 603 a 605, citando también a SALANDRA, BUTTARO, G. CASTELLANO, PICARD \& BESSON, MARGEAT \& FAVRE-ROCHEX, BRIĖRE DE L'ISLE y FANQUE, GARRIGUES, Joaquín: Contrato de seguro terrestre, Madrid 1973, pp. 176 y ss, BENÍTEZ DE LUGO REYMUNDO, Luis: Tratado de Seguros, Volumen II, Madrid, 1955, pp.107 y ss.

6 RUIZ SÁNCHEZ (1988) José Luis: «Las reglas proporcionales y de equidad y el contrato de seguro», en Revista Española de Seguros, AIDA -Sección Española, Editorial Española de Seguros, S. A., $\mathrm{n}^{\circ} .55$, julio/septiembre, 1988, p. 101. GARRIDO Y COMAS, Tratado general de seguros, Teoría y 
En cuanto a las excepciones a la regla proporcional la doctrina ${ }^{7}$ distingue entre las generales y convencionales. Las primeras se enmarcan en dos supuestos, por un lado: Las pólizas de seguros de daños en las que se efectúa una discriminación por objetos y artículos separados, con evaluaciones independientes. Infraevaluados unos y sobrevaluados otros, y que en cuyo caso no se considera indivisible el contrato. En segundo término, el seguro de riesgo locativo, en los supuestos en que un inmueble tiene varios ocupantes y el arrendatario asegurado garantiza el importe del piso que habita, o suscribe un seguro complementario en relación al riesgo que corre dicho inmueble. Respecto de dicho seguro complementario tampoco juega la regla proporcional en cuanto a los daños en el resto del inmueble, siempre que el riesgo locativo principal haya sido asegurado correctamente.

Las excepciones convencionales son las que se derivan del párrafo segundo del art. 30 LCS: "Las partes, de común acuerdo, podrán excluir en la póliza, o con posterioridad a la celebración del contrato, la aplicación de la regla proporcional prevista en el párrafo anterior. La ley de seguros establece que la regla proporcional es de carácter dispositivo, ya que se puede dejar de aplicar por acuerdo de las partes, lo cual va en consonancia con el artículo 2 de la citada ley que dispone el carácter imperativo de la ley, salvo que sus mismos preceptos establezcan otra cosa ${ }^{8}$.

No obstante, lo anterior la jurisprudencia y la doctrina científica han aceptado la posibilidad de excluir la aplicación de la regla proporcional cuando se infiera inequívocamente, su inexistencia, debido a la naturaleza y tipo de contrato. Tal como sucedería en la adopción de algunas modalidades contractuales, como los llamados seguros a primer riesgo, y los ya mencionados relativos a casos de pluralidad de intereses asegurados cubiertos por un mismo contrato de seguro. Otros ejemplos son las pólizas flotantes y los seguros de robo. La no aplicación de la regla proporcional en los mismos se ha visto facilitada no sólo por el deseo de una mayor co-

práctica de los seguros privados, T. I, Teoría general y Derecho español de seguros, Vol. I, p. 119.

7 Conf. CORRALES ELIZONDO (1982) Agustín: «La regla proporcional y la Ley de Contrato de Seguro», pp. 609-610 y 619. BENÍTEZ DE LUGO REYMUNDO, Luis: Tratado de Seguros, Volumen II, Madrid, 1955 Vol. II, pp. 121 y ss. SOTO ABELEDO JAVIER (2011) La regulación del infraseguro, la regla proporcional y la póliza estimada en la ley de contrato de seguro y en el seguro marítimo.

8 Al respecto la jurisprudencia se ha referido a dicha posibilidad entre otras : STS de 3 de abril de 2007, STS de 241/2009, de 20 de abril. 
bertura a favor del asegurado, sino también por la dificultad de determinar el valor de los objetos asegurados, dada su movilidad.

En el seguro a primer riesgo el asegurado establece una suma máxima que garantice la indemnización de determinado riesgo con independencia de su valor. Esta clase de aseguramiento, aunque la suma asegurada sea menor al valor del interés no se aplica la regla proporcional. Se pacta que la aseguradora indemnizará el valor de los daños producidos con el límite máximo del capital establecido como primer riesgo. A pesar de tener la ventaja de evitar el infraseguro, existe el inconveniente que si llegase a producirse un siniestro cuyo daño sea superior al valor establecido como primer riesgo, el seguro no alcance a pagar lo suficiente para reparar o reponer el bien. Esta forma de aseguramiento, es utilizada generalmente en coberturas complementarias a la principal del seguro, por lo tanto, es necesario que exista una pluralidad de intereses sometidos a riesgos diversos y cubiertos por un mismo contrato de seguro, tal es el caso de daños eléctricos, daños a bienes refrigerados, daños estéticos etc. En estos casos se fija un límite máximo a primer riesgo y se paga el daño hasta el límite estipulado sin aplicar la regla proporcional, otros casos son la cobertura principal de incendios, explosión y riegos extensivos en general. De tal manera un mismo siniestro no afectará a los diversos intereses asegurados, por lo que, al ser siempre parcial, la suma asegurada se fijará en función de la pérdida máxima probable, y no de la suma total del valor de todos los bienes. No tendría sentido por lo tanto que el tomador celebrase, una póliza, con la totalidad de valores considerados conjuntamente, ya que el coste del seguro sería tan elevado como desproporcionado teniendo en cuenta que es poco probable que un mismo siniestro afecte la totalidad; o parte de los bienes. Situación deseable para el asegurado quien además verá generalmente resarcido su interés sometido al riesgo. Como la suma asegurada es la de mayor valor, siempre actuará este cómo límite máximo de indemnización para los otros bienes de menor valor, los cuales nunca tendrán el problema del infraseguro, ni tampoco estarán sobreasegurados.

En resumen, se entiende como seguro a primer riesgo a la cobertura de un riesgo, o comúnmente una diversidad de los mismos; con respecto a un interés o varios de ellos, con respecto a una suma asegurada que no corresponde con el valor de la totalidad de ese interés o conjunto de 
intereses y a los cuales no le es aplicable la regla proporcional al no ser un supuesto de infraseguro?

En esta forma de aseguramiento si el que la utiliza es un inquilino, ha de tener cuidado y complementar la cobertura con un seguro de Responsabilidad Civil Locativa, dado que en caso de un siniestro originado por la actividad que se desarrolla en el Inmueble, en caso de superar el capital establecido de primer riesgo no quedaría cubierto el daño y debería responder el inquilino frente al propietario.

Cuando existe otro seguro como por ejemplo un seguro de Comunidad de Propietarios y en un seguro individual se establece un valor a primer riesgo inferior al valor total, este ha de ser suficiente para contemplar los daños de determinados riesgos que no pueden superar el límite establecido.

En la póliza estimada también llamada como valorada o tasada, se posibilita a las partes que de común acuerdo fijen en la póliza o con posterioridad a la celebración del contrato, el valor del interés asegurado que se tendrá en cuenta para el cálculo de la indemnización, lo que no es otra cosa que la fijación convencional del interés; cuestión que deja sin efecto la disposición del artículo 26 relativa a la determinación del daño, teniendo en cuenta el valor del interés asegurado en el momento inmediatamente anterior al siniestro. Así mismo también es una excepción a lo declarado por el artículo 27 de dicha ley según el cual "la suma asegurada representa el límite máximo de la indemnización a pagar por el asegurador en cada siniestro." Lo que conlleva a evitar las dificultades propias de la tasación de las cosas objeto del interés a posteriori, facilitando así la liquidación del daño y el cálculo de la indemnización, quedando el asegurado liberado de la prueba del valor del interés asegurado, pudiéndose evitar así las controversias que se puedan suscitar teniendo además una mayor seguridad jurídica en la relación contractual. $\frac{10}{}$

9 Al respecto el Tribunal Supremo en sentencias del 5 de noviembre de 1999 y 20 de abril de 2009 a dicho : "tiene lugar esta modalidad en supuestos en que se da una pluralidad de intereses asegurados cubiertos por un mismo contrato de seguro; el asegurador se compromete a abonar el total del daño producido en uno de los bienes asegurados, sin que entre en juego la regla de proporcionalidad; se trata en todo caso, de una modalidad del seguro de daños que en modo alguno contradice el que la determinación de los bienes asegurados se relacione por anexos a la póliza".

10 GILMORE, Grant BLACK (1957) Charles L. Jr.: Law of Admiralty, The Foundation Press, Inc. Brooklyn, P 81 
Así se entenderá que una póliza es estimada cuando el asegurador y el asegurado hayan convenido expresamente en ella el valor asignado al interés asegurado. Y por disposición del artículo 28 de la ley de seguros, "El asegurador únicamente podrá impugnar el valor estimado cuando su aceptación haya sido prestada por violencia, intimidación o dolo, o cuando por error la estimación sea notablemente superior al valor real, correspondiente al momento del acaecimiento del siniestro, fijado pericialmente." Debe tenerse en cuenta que los únicos llamados a realizar tal estipulación son las partes en el contrato, es decir asegurador y tomador, por lo cual es errónea la referencia al asegurado como parte en el contrato que hace el párrafo segundo del artículo mencionado, más aún cuando el párrafo primero habla de "las partes". El concurso del asegurado por tanto no es necesario ni suficiente al efecto de convenir el valor asignado al interés asegurado. Esta modalidad de seguro es la expresión ideal de la ecuación: valor del interés asegurado y la muchas veces impuesta suma asegurada, siendo un claro ejemplo de seguro pleno, que servirá además como referencia para calcular la indemnización debida por el asegurador, ya sea si existiese sobreseguro o infraseguro o ya sea que el valor pactado sea mayor o menor al daño realmente producido con respecto al valor de lo asegurado.

Existe la discusión en torno a si la póliza estimada excluye en todo caso la regla proporcional en el supuesto de infraseguro. Para un sector de la doctrina la existencia de dicha póliza es incompatible con la aplicación de dicha regla, argumentando que esta implica una renuncia tácita y en sí misma una excepción convencional. 11

Otro sector de la doctrina opina que ante una situación de infraseguro si no existiese un acuerdo que excluya la regla proporcional, de manera expresa tal como lo establece el artículo 30 párrafo segundo. Incluso tratándose de una póliza estimada, si el siniestro fuere total la suma asegurada será el límite máximo de la indemnización (artículo 27 de la ley de contrato de seguro), y en caso de ser parcial se aplicará la regla proporcional. ${ }^{12}$

11 Confrontar. BENÍTEZ DE LUGO (1955) op. cit., Tratado de seguros, Vol. II, pp. 124 y ss. (citado por CORRALES ELIZONDO, (1988) op. cit., "La regla proporcional...», en VERDERA Y TUELLS y OTROS (1988) Comentarios a la Ley de Contrato de Seguro, Vol. I, p. 622 DEL CAÑO ESCUDERO, op. cit., Derecho Español..., T. I, pp. 444-446.

GARRIDO Y COMAS (1954) op. cit., Tratado general de seguros, Teoría y práctica de los seguros privados, T. I, Teoría general y Derecho español de seguros, Vol. I, pp. 110-111.

12 Confrontar. CORRALES ELIZONDO (1982) op. cit., «La regla proporcional...», en VERDERA Y TUELLS y OTROS (1982) Comentarios a la Ley de Contrato de Seguro, Vol. I, pp. 620-622. RUIZ 
En mi opinión, el pacto que se realiza en la póliza a valor estimado, está encaminada única y exclusivamente a modificar la tasación del interés asegurado, haciéndolo anticipadamente; y como es evidente pueden existir casos en los que incluso con dicha cuantificación anticipada, haya infraseguro. Como lo hemos dicho la razón de ser de la regla proporcional es tratar de equiparar el posible desbalance no ideal de interés y valor asegurado, por medio de una ecuación dispuesta en el ordenamiento jurídico que trata de mitigar dicho desbalance y que en todo caso podría padecer el asegurado al momento de percibir la indemnización como consecuencia del siniestro; y aunque a simple vista la póliza estimada tiene como fundamento el mantener constante el interés asegurado sin que el asegurado padezca el efecto propio de la pérdida de valor por el paso del tiempo, la situación no siempre será de esta manera, puede darse el caso por ejemplo que dicho bien a pesar de haberse pactado con valor estimado, dicha estimación sea muy cercana a la suma asegurada con lo cual el supuesto beneficio que aprovecha el asegurado no sería tan evidente. También se podría dar el caso en que esta clase de estipulación careciera de efectividad; tal situación se daría por ejemplo cuando el valor del bien no varíe a pesar del paso del tiempo, y que la estimación del interés del valor asegurada justo antes del siniestro sea igual a la estipulada en la póliza estimada, no tendría sentido entonces que en estos eventos se excluyera la aplicación de dicha regla, más aún cuando el artículo 30 de la ley de seguro es categórico al exigir que la exclusión a la aplicación de la regla proporcional deba hacerse de común acuerdo por las partes, en la póliza o con posterioridad a esta.

Otra excepción a la aplicación de la regla proporcional es la llamada cláusula de estabilización consagrada en el artículo 29 de la ley de seguro. Según este artículo "Si por pacto expreso las partes convienen que la suma asegurada cubra plenamente el valor del interés durante la vigencia del contrato, la póliza deberá contener necesariamente los criterios y el procedimiento para adecuar la suma asegurada y la primas a las oscilaciones del valor del interés.

El objetivo principal de esta norma es la de evitar la tendencia generalizada de la inadecuada proporción entre suma asegurada y valor

SÁNCHEZ, op. cit., "Las reglas proporcionales y de equidad y el contrato de seguro», en Revista Española de Seguros, $\mathrm{n}^{\circ}$. 55, julio/septiembre, 1988, pp. 94-95. 
del interés. De tal manera que al utilizarla se consigue que la suma asegurada cubra plenamente el interés asegurado, ya sea de una parte o de la totalidad del mismo. Siendo además un requisito sinequanon que el acuerdo deba ser expreso. La intención en este tipo de cláusulas es indudablemente el conseguir una cobertura plena, de allí que la doctrina haya considerado es tal circunstancia sea incompatible con la aplicación de la regla proporcional $1^{\frac{13}{3}}$, de tal manera que lo que se pretende en todo momento del contrato es el equilibrio entre suma asegurada e interés asegurado, es decir el propender por el seguro pleno de acuerdo al artículo 29 de la LCS, el articulo 30 carecería de efectividad, constituyendo así una forma de eludir la aplicación de la mencionada regla. En efecto los seguros contra daños, deben responden al principio indemnizatorio, que implica la reparación del daño efectivamente sufrido, de tal manera que la prestación a favor del asegurado no puede ser superior al daño efectivamente sufrido, conforme a los articulo 1 y 26 de la LCS, es decir el seguro no puede servir de enriquecimiento al asegurado víctima de un siniestro pueda lucrarse injustificadamente a costa del seguro. Por tal razón es este un principio que tiene su razón de ser y su operatividad en relación al contrato de seguro, pero no en las consecuencias jurídicas que se suscitan por fuera de este, de tal manera que su orbital causal se circunscribe única y exclusivamente dentro del contrato de seguro por daños, y por lo tanto la indemnización del asegurador propende por solventar patrimonialmente al asegurado como consecuencia de los daños del siniestro, sin que el asegurado pueda percibir unas ganancias que sobre pasen los límites indemnizatorios propios del tipo de contrato de seguro celebrado.

Es por ello que el principio indemnizatorio no debería ser considerado, como fundamento exclusivo del derecho de subrogación del asegurador para la reclamación al tercero responsable del daño, con la consecuencial perdida de legitimación del asegurado para actuar contra este. Esta ecuación es por tanto aplicable única y exclusivamente al ámbito contractual, pero no a la relación entre el asegurado ya indemnizado por el asegurador y el tercero ajeno al contrato de seguro ${ }^{14}$. De la

13 Confrontar. CORRALES ELIZONDO (1982) op. cit., «La regla proporcional...», en VERDERA Y TUELLS y OTROS op cit, Comentarios, pp. 622-623. RUIZ SÁNCHEZ (1988) op. cit., «Las reglas proporcionales y de equidad y el contrato de seguro», en Revista Española de Seguros, nº. 55, julio/ septiembre, 1988 , p. 97.

14 La doctrina italiana ha señalado que el principio indemnizatorio como fundamento de la subrogación 
misma forma con ocasión de un siniestro cubierto por el seguro y en la eventualidad que se diera la responsabilidad de un tercero, el asegurado tiene dos opciones, por un lado, reclamar el resarcimiento de los daños sufridos dirigiéndose directamente al asegurador y por otro dirigirse contra el tercero responsable. En este último caso si efectivamente el tercero responsable resarciera los daños causados directamente al asegurado; y en virtud del mencionado principio el asegurado no podrá obtener por ese mismo daño la indemnización derivada del contrato de seguro. de tal manera que, al ser indemnizado por el tercero, el daño causado seria resarcido y en consecuencia desaparecería el interés asegurado, careciendo de sustento la indemnización del asegurado. En caso contrario se estaría atentando contra el principio indemnizatorio, ya que el seguro se convertiría en una fuente de lucro para el asegurado debido a la inexistencia del daño.

Por el contrario, si el asegurado opta por dirigirse en primer lugar al asegurador y este le indemniza en la totalidad del daño, podrá luego dirigirse contra el tercero responsable y percibir la indemnización por parte de este incluso sin descontar la cantidad pagada por el asegurador, al no existir vulneración del principio indemnizatorio. De tal manera que no se desconocería el precepto del artículo 26 LCS, ya que este es suficientemente claro al circunscribir el enriquecimiento injustificado por parte del asegurado al ámbito exclusivamente contractual del seguro. Es además este artículo una reiteración de lo ya expuesto en el sentido que el daño no se fundamenta en el principio indemnizatorio sino en la prohibición del enriquecimiento injusto, por lo tanto, su derecho no solamente estaría limitado por los preceptos contractuales, sino que se extendería a la situación circunstancial que le dio origen. Debe entenderse como lo ha dicho la doctrina que la diferencia entre el derecho de daño y el derecho indemnizatorio es que el primero se fundamentan en una función indemnizatoria, mientras que el segundo pertenece al derecho de enriquecimiento, es decir que sus normas tienen como principal objetivo la reintegración o la sustitución de valores patrimoniales obtenidos mediante el ejercicio indebido de un derecho ajeno. Por lo tanto, la pretensión derivada de daños y perjuicios se orienta a la consecución

y que evita el doble enriquecimiento injustificado por parte del asegurado, se ha venido dejando de utilizar por parte de la jurisprudencia italiana. RIGHETTI, G (1994) Trattato di Diritto Maritimo, Milano, 1994, P. 628. 
de una indemnización; mientras que la pretensión de enriquecimiento se encamina contra el enriquecimiento sin justa causa para obtener la restitución de la cuantía del enriquecimiento..$\underline{15}$

\section{LA SUBROGACIÓN PARCIAL DEL ASEGURADOR}

La cotitularidad del derecho de crédito frente al tercero responsable en los casos de subrogación parcial.

La subrogación implica una novación subjetiva, de la relación obligatoLa subrogación implica ${ }^{\frac{16}{6}}$ una novación subjetiva, de la relación obligatoria sin que se modifique el objeto de esta. Dicho principio debería también ser transmisible en los casos de subrogación parcial, de tal manera que no se extinguiría en principio el derecho de crédito originario, pero con la salvedad que se crearían dos nuevos derechos de crédito, uno a favor del asegurado y el otro a favor del asegurador. De tal manera que el derecho de crédito seguirá siendo el mismo, existiendo una especie de cotitularidad. La naturaleza jurídica de esta especie de cotitularidad puede ser diversa ya sea en régimen de mancomunidad, del artículo 1138, el cual presupone que la solidaridad activa debe ser estipulada, de lo contrario se entenderá que existe un régimen de cotitularidad mancomunada sobre el derecho de crédito, frente al tercero responsable, que no necesariamente debe ser ejercido simultáneamente por parte de asegurado y asegurador; dividiéndose el crédito en tantas partes o acreedores, existan, constituyéndose el derecho a la prestación en varios derechos de crédito independientes entre sí con un sujeto como titular del mismo. La doctrina sobre el tema coincide en afirmar que la presunción de mancomunidad tratada, se desvirtúa por el artículo 43 LCS, al disponer que la subrogación del asegurador en el crédito tiene como límite la indemnización pagada, permaneciendo como titular del crédito el asegurado por la cuantía restante. ${ }^{17}$ Sin embargo el artículo mencio-

15 DÍEZ PICAZO Y PONCE DE LEÓN (2011) Fundamentos del derecho civil patrimonial, Vol V 1 ed, Aranzadi, Pamplona, 2011, pp 28-51. La SAP de León (sección 2), de 18 de febrero de 2009, Ponenete Alberto Francisco ÁLVAREZ Rodriguez, (JUR 2009/189259),

16 Sentencia del Tribunal Supremo de 13 de febrero de 1988 en la cual ratifica la idea consagrad en el artículo 1213 C.C. en el sentido que la cesión de crédito implica un cambio en el elemento personal de la relación jurídica quedando inalterado lo demás. De tal manera que el cesionario no respondería de una obligación distinta sino de la misma obligación frente al cedente.

17 TATO PLAZA (2002) a subrogación del asegurador en la ley de contrato de seguro, Ed. Titant lo 
nado no establece expresamente lo último; es decir que el asegurado solamente tendría derecho a la cuantía restante en caso de concurrencia de acciones por parte de asegurado y asegurador, lo que sí se podría decir es que ni asegurado ni asegurador pueden en perjuicio del otro ejercer acción que limite su derecho al crédito frente al tercero responsable. Así mismo el primer párrafo de la mencionada disposición, plasma como ya lo dijimos el principio de no enriquecimiento por parte del asegurado, como consecuencia del pago del seguro por parte del asegurador. Sería desproporcionado por demás pensar que el asegurador tenga prevalencia en el cobro del crédito siendo que por un lado el patrimonio que se afecta como consecuencia del siniestro, en relación a la cobertura, y bien asegurado sea directamente el de este último; y por el otro que la citada disposición es clara al disponer un principio de equidad al determinar que en caso de subrogación parcial tanto subrogado como subrogante deberán realizar el recobro en proporción a sus respectivos intereses. Interpretar la disposición en este sentido, desconoce el derecho que tiene el asegurado a la reparación del daño causado en su patrimonio, ya sea como consecuencia directa del contrato de seguro como de la responsabilidad consecuente que se deriva de este. No considero que los únicos efectos patrimoniales que surgen del contrato de seguros se deriven de la suma asegurada o del valor del interés asegurable, precisamente el mismo artículo 43 LCS, prevee efectos más allá del contrato, $\frac{18}{}$ al conceder prerrogativas al asegurado de reembolso como consecuencia de la responsabilidad del tercero responsable, que incluso podría estar por fuera de la cobertura del seguro y de la suma debida, contractualmente estipulada. A modo de ejemplo una persona decide asegurar por $60 \mathrm{su}$ interés vinculado a la propiedad de un automotor que realmente vale 100, y ocurre un siniestro que destruye el vehículo en un 50\%; en virtud de la aplicación de la regla proporcional, y el deducible la compañía solamente cancelará 30. Es claro que la ley permite al asegurado ir en contra el tercero responsable en proporción a su interés patrimonial real, es decir por los 70 restantes y no únicamente por 30, siendo esta ultima la cuantía máxima de la diferencia entre lo pagado por la aseguradora y el interés asegurado por el contrato.

Blanch, valencia 2002, p 158.

18 Incluso el ejercicio del derecho del art. 43 de la Ley de Contrato exige que la compañía aseguradora pruebe los elementos constitutivos de la acción de responsabilidad extracontractual y la negligencia del demandado. véase la STS, $1^{\text {a }}, 24.1 .2002$; la STS, $1^{\text {a }}, 13.2 .2001$; la STS, $1^{\text {a }}, 17.10 .1998$; y la STS, $1^{\mathrm{a}}, 5.2 .1998$. 
Debe tenerse en cuenta que este derecho que le acoge al asegurado tiene una naturaleza esencialmente recuperatoria ${ }^{19}$ y es por esta razón que el asegurador no puede pretender mediante el ejercicio de su derecho obtener una ganancia injustificada. $\stackrel{20}{ }$ Incluso si el monto de lo debido fuese fijado con posterioridad y este fuese mayor o menor el único derecho que le acogería sería el monto de lo realmente pagado. $\underline{\underline{21}}$

De tal manera que si el derecho de subrogación del asegurado tiene como límite el importe de lo pagado existirá una subrogación parcial en todos los eventos en que dicho monto no cubra el total de los daños. Debe tenerse en cuenta que la mayoría de los casos el importe de lo pagado al asegurado como consecuencia del siniestro no es suficiente para solventar el daño causado, ya sea como consecuencia de un infraseguro, de la deducción como consecuencia de un deducible, una liquidación inferior como consecuencia de un acuerdo conciliatorio, e incluso como consecuencia de la fórmula de póliza estimada del artículo 28 de la ley de seguro que posibilita a las partes contratantes de seguros de daños a que excepcionalmente las partes, de común acuerdo, fijen en la póliza,

19 Garrigues Diaz - Cañabate Joaquín, contrato de seguro, terrestre. Madrid 1973, p 255,

20 Sobre este límite, la jurisprudencia es reiterada al entender que la acción subrogatoria que le acoge al asegurado, le faculta a reclamar frente a la persona responsable del siniestro únicamente el monto de lo pagado. Cfr. Audiencia provincial de Barcelona de 7 de septiembre de 1998, sentencia de la audiencia provincial de Madrid de 15 de julio de 1998, STS 2013/2011 Tribunal Supremo. Sala de lo Civil, en esta última se se señala lo siguiente: "lo cierto es que esta Sala no puede por menos de considerar, como criterio básico para la desestimación de la pretensión que se articula, el contenido literal del artículo 43 de la Ley de Contrato de Seguro que, en los supuestos como el que es objeto de este debate, de ejercicio de una acción subrogatoria (con independencia del alcance teórico que quiera darse a esa figura), permite esa acción "hasta el límite de la indemnización". Si la entidad aseguradora -por cualquier motivo- únicamente ha satisfecho una parte de la cantidad, solamente tiene reconocido el derecho a repetir la que ha satisfecho y cualquier otra conclusión sería contraria a la norma que autoriza el derecho mencionado.

21 Sobre este límite, la jurisprudencia es reiterada al entender que la acción subrogatoria que le acoge al asegurado, le faculta a reclamar frente a la persona responsable del siniestro únicamente el monto de lo pagado. Cfr. Audiencia provincial de Barcelona de 7 de septiembre de 1998, sentencia de la audiencia provincial de Madrid de 15 de julio de 1998, STS 2013/2011 Tribunal Supremo. Sala de lo Civil, en esta última se se señala lo siguiente: "lo cierto es que esta Sala no puede por menos de considerar, como criterio básico para la desestimación de la pretensión que se articula, el contenido literal del artículo 43 de la Ley de Contrato de Seguro que, en los supuestos como el que es objeto de este debate, de ejercicio de una acción subrogatoria (con independencia del alcance teórico que quiera darse a esa figura), permite esa acción "hasta el límite de la indemnización". Si la entidad aseguradora -por cualquier motivo- únicamente ha satisfecho una parte de la cantidad, solamente tiene reconocido el derecho a repetir la que ha satisfecho y cualquier otra conclusión sería contraria a la norma que autoriza el derecho mencionado.

Prosigue la mencionada sentencia. "Si la entidad aseguradora -por cualquier motivo- únicamente ha satisfecho una parte de la cantidad, solamente tiene reconocido el derecho a repetir la que ha satisfecho y cualquier otra conclusión sería contraria a la norma que autoriza el derecho mencionado". 
o con posterioridad a la celebración del contrato, el valor del interés asegurado que se tendrá en cuenta para calcular la indemnización en caso de producirse el siniestro.

La póliza en la que se manifieste expresamente la aceptación de ambas partes respecto al valor asignado al interés asegurado es la llamada póliza estimada. Teniendo en cuenta que este valor será por lo general inferior al valor real ya que le acoge al asegurado el derecho de impugnar dicho valor estimado cuando éste, por error, sea notablemente superior al valor real, correspondiente al momento del siniestro, fijado pericialmente. Por tanto al ser el pago inferior al interés asegurado no cubriría el total del derecho de crédito frente al tercero responsable, pero que debería corresponder con el daño efectivamente sufrido por el asegurado, de tal manera que este solo ha sido resarcido parcialmente, conservando así por ministerio de la ley un derecho de crédito contra el tercero en la parte del derecho restante que correspondería a los daños sufridos y no cubiertos por el asegurador.

\section{INSUFICIENCIA DEL CRÉDITO FRENTE AL TERCERO RESPONSABLE EN CASO DE SUBROGACIÓN PARCIAL}

La situación ideal en caso de subrogación parcial sería que el crédito generado como consecuencia de la responsabilidad surgida de un tercero sea suficiente para solventar, el interés tanto de la aseguradora como la del asegurado, y así no generar un perjuicio patrimonial para ninguno de los cotitulares de la acción. De tal manera que el asegurador se subroga en el crédito hasta el límite de lo pagado al asegurado lo que le permite recuperar íntegramente el valor pagado como consecuencia de la responsabilidad del tercero. Y a su vez el asegurado podrá ir por la diferencia entre el importe del interés asegurado y la suma efectivamente pagada por el asegurador. Es decir que no existiría problema en caso que el importe del crédito a cargo del tercero responsable del siniestro sea igual al de los daños sufridos al patrimonio del asegurado, quedando así indemne su patrimonio, como consecuencia de la insuficiencia de crédito por el pago parcial realizado por la aseguradora. 
De tal manera que se plantea el problema de cómo se regla el concurso entre asegurador y asegurado en caso de insolvencia del tercero responsable del siniestro, que le impida reparar íntegramente el daño del cual fue responsable. Sobre esta disyuntiva le articulo 43 LCS, contrariamente a lo dispuesto por el código civil determina que en caso de que concurran estos dos derecho de crédito, la reclamación frente al tercero se repartirá entre ambos en proporción a su respectivo interés. El problema se suscita cuando existe insolvencia por parte del tercero responsable, a lo cual entendemos como fue expuesto en apartes anteriores que esta proporción estaría determinada por la afectación del patrimonio del asegurado en función del pago parcial recibido por el asegurado, teniendo en cuenta que es el patrimonio del asegurado el directamente afectado a consecuencia del daño ocasionado por el tercero responsable. No solamente es claro que las consecuencias directas del siniestro recaen sobre el patrimonio del asegurado sino que la legislación en su artículo 43 LCS establece explícitamente que la subrogación no procede cuando su ejercicio cause un perjuicio a los derechos del asegurado. Es claro que ante el caso de infraseguro acompañada de insolvencia por parte del deudor, esta debe aplicarse conforme al daño real causado al patrimonio de este, y no con respecto a las sumas aseguradas como consecuencia directa del contrato de seguro. De tal manera que se debe entender que la idea de la proporcionalidad del interés del asegurado y el asegurador respecto del tercero resulta entendible desde el daño causado al patrimonio del asegurado, de no ser así se verían claramente vulnerados sus derechos. Será entendible entonces que cuando el asegurador rivalice con el asegurado quien ha sido indemnizado parcialmente, deberá resolverse en favor de este y no de la compañía de seguros más aún cuando así lo prevé el artículo 1213 del C.C. $\underline{22}$ Así mismo debe tenerse en cuenta que los seguros de daño procuran la reparación del daño patrimonial por el siniestro causado al asegurado, estableciendo así la obligación incondicional por parte del asegurador de indemnizarlo. $\underline{23}$

22 "El acreedor, a quien se hubiere hecho un pago parcial, puede ejercitar su derecho por el resto con preferencia al que se hubiere subrogado en su lugar a virtud del pago parcial del mismo crédito" La regla de la subsidiariedad, de acciones contra el tercero responsable en proporción a los respectivos intereses es dable aplicarlo a los casos de seguro múltiple o coaseguro, en los que vario aseguradores pueden coincidir como consecuencia de un mismo siniestro.

23 Este criterio es respaldado ampliamente por la doctrina. RUIZ SOROA, J.M (1984) fundamentos de la subrogación legal del asegurador, en ADM, vol II, 1984, p 347, Tato Plaza A, cit, p 174-175. CALZADA CONDE M, A (2008) la subrogación del asegurador y la protección de los intereses de los asegurados en RDM, N 270, 2008. SÁNCHEZ CALERO (1999) ley de contrato de seguro. Comentario al a ley $50 / 1980$, de 8 de octubre, y a sus modificaciones, Aranzadi, Pamplona pág. 664. 
Es claro que es el asegurador quien debe asumir los riesgos inherentes a su actividad económica, teniendo el deber incluso de no recobrar en su totalidad lo pagado al asegurado; así mismo el contrato de seguro tiene como función proteger económicamente el patrimonio del asegurado, en contraprestación a la prima pagada por el asegurado y por lo tanto no tendría sentido que este se utilice como herramienta para disminuir el patrimonio del asegurado, ya que se estaría desvirtuando además uno de sus elemento casuístico y esenciales como es el de la estabilización y protección del patrimonio del asegurado.

La idea que se ha tratado de defender a lo largo de este escrito, consistente en que el asegurado pagado parcialmente esté legitimado para exigir del tercero responsable el faltante de su interés patrimonial, con preferencia al derecho que le asiste al asegurador, sería también extensible en los casos en que el tercero responsable del siniestro sea parcialmente solvente, tal es el caso en el que la indemnización pagada por el asegurador sea inferior al daño padecido por el patrimonio del asegurado, y el tercero no puede resarcir íntegramente ese daño por ser parcialmente insolvente, en tal situación al realizar las acciones y reclamaciones correspondientes deberá priorizarse el interés del asegurado y no el del asegurador, ${ }^{24}$ problema que no se suscitaría en el caso en que el tercero responsable fuese totalmente solvente.

Es así como la indemnización como consecuencia del seguro es un pago a título de anticipo y de manera provisional, ya que el importe total será recuperado cuando el asegurador vaya contra el tercero, deduciendo la parte ya entregada al asegurado ${ }^{25}$, en estos casos el dinero al cual se compromete en caso de asumir el riesgo de un siniestro del contrato será recuperado en su totalidad, lo que implica que en los caso en que exista un tercero responsable del siniestro ya sea total o parcialmente su función solamente se circunscribirá a la de financiar anticipadamente el perjuicio causado a su asegurado, de manera temporal. Por ello los gastos en que incurriría el asegurado solamente se limitarían a los administrativos, y

24 V RUIZ SOROA, J.M (1975) La subrogación de asegurador. Especial referencia al seguro Marítimo, Tesis doctoral inédita, San Sebastián p 347. HERNANDEZ MARTÍ J (2002) comentario Art 43 LCS, en comentario a la ley de contrato de seguro p 546 TATO PLAZA (2002) La subrogación del asegurado en la ley de contrato de seguro pp 174.175; CALZAFDO CONDE, M, A (2008) La subrogación del asegurador y la protección de los intereses de los asegurado p 1429-1434, en.......

25 GENOVESE, A (1970) iI limiti della surroga dell assicuratore, en A.I.D.A; Estudi in onore di Antigono Donati, Roma, 1970, pp 349-376. 
de financiación sin asumir un verdadero riesgo. En efecto se entiende que la prima aparte de ser el elemento real y esencial más importante del seguro, es una aportación económica que hace el contratante o asegurador al asegurado en concepto de contraprestación por la cobertura del riesgo que este le ofrece.

Es esta relación simbiótica una de las más importantes en este tipo de contrato. De tal manera que las partes deben procurar por mantener dicha relación simbiótica, sin desnaturalizarla ni alterarla, tal sería el caso en que el asegurador pretendiese tener un derecho prioritario sobre el crédito del tercero responsable. $\mathrm{Y}$ aunque hipotéticamente puedan existir casos en los que el asegurador recupere la totalidad del anticipo o financiación en caso de subrogación, este debe propender por respetar la máxima de asumir un verdadero riesgo que pueda causarle perjuicio al patrimonio del asegurado, ya que de todos modos este tiene el beneficio de la prima que no será otra cosa que el coste de probabilidad media teórica más otra serie de rubros, esto quiere decir que la prima es proporcional a la duración del seguro, el grado de probabilidad del siniestro y la suma asegurada, pero el asegurador no se limita a cobrar al asegurado el precio medio de esa probabilidad (prima pura o de riesgo), sino que incluye gastos de administración tales como cobro de primas, tramitación de siniestros haberes de personal de la empresa etc, así como gastos de adquisición como comisiones de primas, marketing, o gastos de redistribución de riesgo como coaseguro y reaseguro. Pero aun así la entidad aseguradora ha de satisfacer otra serie de gravámenes que repercuten sobre la prima comercial y que se denominan impuestos accesorios los cuales constituyen la prima total y que están a cargo del asegurado. Es cierto que el asegurador cuando paga la indemnización como consecuencia del acaecimiento del siniestro cumple con su deber de prestación principal que contrajo al asumir el riesgo amparado a cambio de la prima, en observancia además del principio de buena fe, en su accionar objetiva, y es también un hecho que por regla general, en la relaciones contractuales debe existir un equilibrio que permita a la compañía de seguros de acuerdo a los principios del cálculo de probabilidad y previsión de lo imprevisible, no sufrir una disminución con ocasión del pago del siniestro con respecto a su objeto social, en condiciones de normalidad, y por ende satisfacer los intereses de la masa aseguradora, ratio medular de su actividad, estas circunstancias no tienen virtualidad de impedir que el asegurado realice el recobro o recupero como se ha dicho en la práctica aseguradora como consecuencia de la subrogación descrita en la 
norma. Sin embargo esta acción no es un reembolso propiamente dicho ya que no persigue obtener el equilibrio de la relación asegurativa, la cual si debería alcanzarse atreves de la prima, y por ello concebida expressis verbis como precio del seguro, en concordancia con un adecuado programa de reaseguros y de inherente gestión empresarial (manejo de reservas, inversiones, etc.), sin que en todo caso se pueda desvirtuar su naturaleza especulativa, nada despreciable ni desdeñable, que como lo confirma un sector de la doctrina, es el asegurador mediante este recobro, recupero o acción, como indirectamente puede obtener unos recursos suplementarios que le permitan una mejor explotación del negocio del seguro, inequívocamente en beneficio de la masa aseguradora ${ }^{26}$. De tal manera que el cumplimiento de la prestación asegurada por el asegurador no puede ser considerado como detonante de un daño o un perjuicio al asegurado, dado el previo cobro de la prima.

De tal manera que no es descabellado afirmar por vía de ilustración que el fundamento de la subrogación no es solamente la de proteger pecuniariamente al asegurador, quien por el contrario fundamenta su negocio en el cobro de la prima encontrando así la contraprestación económica de sus compromisos, siendo dentro de la relación aseguradora que se fija el equilibrio contractual el cual en virtud de los principios de cálculo de probabilidad y la previsión de lo imprevisible se deteriore ni sufra daño alguno cuando este paga al asegurador la indemnización, cumpliendo lo pactado, de tal manera que las sociedades aseguradoras no se empobrecen por pagar lo que debe en razón de un contrato cuya singular estructura le permite la contraprestación económica con base en principios técnicos, ${ }^{27}$ ni como se había dicho y lo esclarece la ley de seguro el cumplimiento de la prestación asegurada por el asegurador no puede ser el detonante de un daño o de un perjuicio, propiamente dicho y menos cuando afecta directamente su patrimonio, dado el previo cobro de la prima. ${ }^{28}$

26 CF. FERNANDO SÁNCHEZ CALERO (1999) Ley de contrato de seguro. Aranzadi, Pamplona pág. 652. WALTER VILLA ZAPATA (1997) La subrogación en el derecho de seguros peruano. En: Revista Ibero-Latinoamericana de Seguros. No X, Bogotá, 1997, p 151.

27 El profesor J. EFRÉN OSSA, certeramente anota en su obra que "el temor de que el asegurador pueda enriquecerse por la vía de la subrogación carece de todo fundamento porque, merced al principio de la comunidad de suerte entre asegurador y reasegurador, el carácter indemnizatorio del reaseguro, el derecho a la subrogación que corresponde - in integrum - al asegurador ha de ser compartido por el reasegurador en proporción a la cuota en la indemnización del daño asegurado". Teoría general del seguro. T. II, op. cit., pág. 185, ARIEL FERNÁNDEZ DIRUBE (1993) Manual de reaseguros. Biblioteca General Re. Buenos Aires pág. 208. 
Se podría pensar entonces que la razón de ser de la subrogación estriba en su carácter indemnizatorio razón por la cual no puede ser fuente de ganancia o riqueza, esta apreciación sería válida desde el punto de vista del asegurado pero no con respecto al asegurador. En efecto al producirse la subrogación el legislador pretende que el asegurado no reciba una indemnización ni superior ni inferior al daño realmente sufrido, en el primer caso la ley otorga al asegurador la acción subrogatoria,: y en el segundo caso le impide al asegurador cobrar para si aquella parte del daño no cubierto, pero la norma no prohíbe en favor el asegurador una ganancia adicional, no necesariamente en beneficio del asegurador y en perjuicio del asegurado. De tal manera que es errónea la apreciación según la cual como el contrato de seguros no puede ser fuente de ganancias y menos de riqueza sino que se caracteriza por ser indemnizatorio, siendo obvio que se circunscriba el derecho del asegurado que ha pagado el valor del seguro a obtener del autor del daño, únicamente el monto de la suma pagada y no de una suma superior. El argumento es erróneo porque el carácter indemnizatorio que reviste al seguro de daños es aplicable solamente al asegurado quien no recibiría una indemnización superior al valor del daño realmente sufrido. Y cuando la norma establece que el asegurador se subroga hasta el monto de lo pagado lo que esta es aplicando principios generales de la teoría general de las obligaciones según las cuales el asegurado conserva el derecho de cobrar aquella parte del daño no cubierto por el seguro. En ninguna parte el supuesto carácter indemnizatorio del seguro impide al asegurador cobrar lo pagado como dinero adicional a su gestión y asunción del riesgo en el contrato, que además de ser una realidad jurídica también es una realidad fáctica, y es por ello que el asegurador no puede ser obligado a pagar sino el valor de la perdida realmente experimentada por el asegurado; y por consiguiente, para la estimación de la pérdida sufrida debe tomarse como base el valor de los objetos asegurados en el momento del siniestro, con deducción del valor apreciable que tengan los despojos o la utilidad restante del bien o bienes asegurados, esa es la idea que se ha plasmado en este escrito en cuanto a la afectación real en el patrimonio del asegurado, siendo principio fundamental devolver el patrimonio del asegurado al estado en que se encontraba antes del siniestro, como si los bines amparados por la póliza hubieren estado asegurados por un valor real, que tratándose de bienes corpóreos dicha finalidad se satisface si el asegurado recibe una suma adecuada para adquirir en el mercado un bien de las mismas 
características o para reparar el objeto dañado parcialmente hasta dejarlo como antes del siniestro. Incluso encontramos un ejemplo llevado al extremo en la jurisprudencia chilena que llega a afirmar que el monto de la indemnización con relación al costo de reparación en un edificio debe tener en cuenta materiales nuevos, cuestión que sin embargo representaría una ganancia al asegurado que se traduciría en el mayor valor que lógicamente adquiere el edificio reconstruido, lo que estaría en pugna con el artículo 517 del código de comercio de este país con respecto a que el contrato de seguro es "de mera indemnización, y jamás puede ser para él la ocasión de una ganancia."르.

\section{LA SUBROGACIÓN EN GENERAL Y SU RELACIÓN CON EL SEGURO}

Cuando nos referimos a la subrogación nos preguntamos si esta, extingue la obligación existente, o si por el contrario esta se transmite en una tercera vía, existiendo una suerte de pago en el que se produce un desdoblamiento de la obligación; extinguiéndose por un lado el crédito con el acreedor originario, pero también subsistiendo la deuda con el deudor primitivo y ahora en favor del nuevo acreedor subrogante. Se podría pensar que el efecto jurídico aparente del pago con subrogación es que la obligación que resulta del crédito originario permanece subsistente produciéndose solamente un cambio de personas alrededor del acreedor, ya que el originario ha sido reemplazado por el subrogante, con todos los mismos derechos y obligaciones que aquel.

Para entender tal planteamiento debemos remontarnos a los orígenes de la figura en la legislación española, haciendo lo propio con los orígenes de la subrogación del seguro, con la finalidad de entender si las figuras nacen con una concepción y unas causas análogas, o si por el contrario estas dos instituciones tienen una conformación y finalidades disimiles.

El anteproyecto de 1888 del código civil español introduce el pago por subrogación dentro de la sección de la novación, al igual que se encauza en el

29 Proceso arbitral "Ana Undurraga Laso c/Cía. La previsora y la Chilena consolidada; árbitro Superintendencia de Valores y Seguros; 12/02/1938. 
actual código. Por su parte el proyecto de 1851 en su artículo 1086 señala que entre las causas extintivas de las obligaciones al igual que el cumplimiento o pago se encuentra la delegación o subrogación. La sección II dedicada al pago o cumplimiento, la III a la subrogación y la sección $\mathrm{V}$ a la novación. Por su parte el artículo 1099 referido al pago señala que puede hacerse por cualquier persona que tenga algún interés en el cumplimiento de la obligación, o por un tercero no interesado siempre y cuando el deudor así lo acepte expresa o tácitamente. En este último caso el tercero tendrá derecho para repetir contra el deudor lo que hubiere pagado, siempre y cuando no lo hubiere hecho contra la voluntad del deudor, caso en el cual no podrá repetir contra este. $\frac{30}{}$

De lo anterior podemos decir que el acreedor no puede reusarse a recibir el pago y que incluso puede el tercero pagar aun en contra del deudor, caso en el cual no podrá dirigirse contra este por dicha suma pagada. Y en todo caso el pago extinguirá la obligación, y que la motivación del tercero que paga no es en sí mismo el crédito sino los derechos que lo acompañan; en general los privilegios y las hipotecas.

Por otro lado el anteproyecto en su artículo 1226 que retoma el 1209 del actual código establece que la subrogación de un tercero en los derechos del acreedor, no puede presumirse fuera de los casos expresamente mencionados en este código. En los demás será preciso establecerla con claridad para que produzca efectos ${ }^{31}$. A su vez el artículo 1210 del actual código presume que hay subrogación en los siguientes casos: 1 . Cuando un acreedor pague a otro acreedor preferente 2. Cuando un tercero, no interesado en la obligación, pague con aprobación expresa o tácita del deudor. 3. Cuando pague el que

30 En cuanto al pago ignorándolo el deudor, señala CAÑIZARES LASO (1996) citando a GARCIA GOYENA (1974) que el interés del acreedor se circunscribe a ser bien pagado, venga de cualquiera que sea y tampoco puede permitir la ley que unos terceros maliciosos o vengativo tenga derecho para subrogarse en los privilegios hipotecas y facultad del acreedor para el apremio personal.

31 DIEZ PICAZO (2011) reitera la idea recogida en la ley que la subrogación no opera automáticamente, sino que se limita a presumir un convenio de subrogación automáticamente, que igualmente no debe ser probado, por aquel que quiera hacerla valer. Cabe anotar que al no incorporarse las ideas del anteproyecto de 1851 en al actual código civil referentes a la imposibilidad del tercero de repetir, en el evento en que la subrogación se hace en contra del deudor, en efecto el artículo 1210 del actual código estipula de manera clara que el pago que realiza un tercero de una deudo puede realizarse con o sin la aquiescencia del deudor, y mediando o no interés por parte del tercero, por lo cual la presunción que establece la ley sería única y exclusivamente referente a la intención del tercero que paga en subrogarse, lo cual se traduciría en la intención de ir por las hipotecas o garantías del deudor o ejercitar el derecho de crédito que le acoge según el artículo 1212, que establece que al surtirse la subrogación esta transfiere al subrogado el crédito con los derechos a él anexos, ya contra el deudor, ya contra los terceros, sean fiadores o poseedores de las hipotecas. Por tal motivo será quien alega su inexistencia quien deba probar. 
tenga interés en el cumplimiento de la obligación, salvos los efectos de la confusión en cuanto a la porción que le corresponda.

Es claro entonces que el efecto natural de las subrogaciones es extinguir la obligación respecto del acreedor aunque queda inamovible a favor del subrogado quien puede ejercitar los derechos, garantías e hipotecas contra el deudor. De tal manera que la subrogación por esencia no es un negocio de enajenación de derecho o venta de acciones en contra de un deudor ya que el consentimiento del nuevo deudor o del ahora acreedor no son necesarios.

Queda además claro que el pago del tercero que paga es una acción extintiva de las obligaciones y es así que lo quería el legislador al suprimir en el anteproyecto y posteriormente en actual código la posibilidad que sin existir pacto, el tercero que realiza el pago se subrogue específicamente en los derechos que tenía el acreedor pagado con respecto a las acciones, privilegios o hipotecas contra el deudor. Este tipo de subrogación deberá entonces ser expresa y hacerse al momento del pago. De tal manera que al darle alcance al artículo 1212 del actual código y 1229 del anteproyecto debe entenderse que los derechos que eventualmente se transfieran en virtud de la subrogación son derechos anexos al propio crédito y no como la prolongación de la obligación primigenia, esto solo sería posible mediante el pacto, y es que tal como lo establece el artículo 1204 del actual código no solamente la obligación queda extinguida por otra que la sustituya en el preciso evento en que así se declare, sino que también cuando la antigua y la nueva sean incompatibles. Es evidente que las obligaciones que llevan al pago con subrogación son diferentes en todo aspecto diferentes por un lado el negocio primigenio entre deudor y acreedor puede tener como causa un sin número de negocios o actos jurídicos, por otro lado las causas y la razón del pago con subrogación junto con sus efecto obligacionales derivados principalmente de la ley son como lo entendió el derecho romano desde sus inicios el poder ir por las garantías que el antiguo acreedor ostentaba.

Por su parte la antigua legislación francesa recoge las figuras del successio in locum y el beneficium que posteriormente se incorporaron al códigos civiles italiano y español. La doctrina francesa es clara al entender que el pago tiene efectos extintivos es decir desaparece el derecho de crédito del acreedor con respecto al deudor. $\frac{32}{32}$

32 MAZEUD- MAZEUD-CHABAS (1991) Lecons de Droit Civil, II, Paris, 1991, pp 954 y ss. 
El derecho español ha entendido que el pago con subrogación derivado de la doctrina italiana entiende en su mayoría que la subrogación transmite el crédito ${ }^{33} \mathrm{y}$ al parecer es este el efecto aparente derivado del artículo 1212 del código civil. Es clara la influencia que tuvo el código napoleónico que recoge posteriormente el antiguo derecho francés en el sistema jurídico español e italiano. La doctrina francesa es homogénea al entender que el efecto del pago en la subrogación es extintivo a diferencia de la doctrina española. A diferencia de las mencionadas legislaciones el código español incluye la subrogación dentro del capítulo de la novación incluida dentro del capítulo de la extinción de las obligaciones, en concordancia con el proyecto de 1851 que regulaba el pago la novación y la subrogación como ejemplos de extinción de las obligaciones. Lo que debemos entender sobre el tema es en que forma el tercero que paga se subroga tomando en todo caso el lugar del acreedor; es el mismo crédito el que puede ejercer, con las garantías accesorias que lo acompañan, o es el crédito el que se extingue por el pago y el subrogado tiene una acción personal que nace del pago peor garantizados con los privilegios e hipotecas y cauciones, que son propios del crédito que el tercero pagó, y que la ley acoge como un efecto del pago de dudas ajenas para evitar como vimos el enriquecimiento del deudor asegurando en todo casos con las mencionadas garantías. Y si es así como sería en el caso de la subrogación en el contrato de seguros, el límite estaría impuesto por una especie de ficción como lo ha entendido la doctrina contemporánea al código napoleónico una transmisión ficticia del crédito que claramente tiene una causa diferente al negocio primigenio dichas cuestiones son de suma importancia a la hora de entender cuáles garantías hipotecas o como lo dice la legislación española derechos en una aparente acepción más amplia. Y es que el efecto práctico de tales circunstancias nos llevaría a entender que la subrogación está limitada por dicha concepción.

Si entendemos la cuestión dentro de la concepción francesa del pago como extintivo del crédito por el pago dicho crédito no podría pasar al subrogado. En realidad lo que se transmitiría serían las garantías personales y reales que acompañan exclusivamente al crédito, es decir que quien paga una deuda ajena ocupa el lugar del antiguo deudor pero no persigue el crédito primigenio, sino su propio crédito derivado del pago

33 Autores citados por SANCHO REBULLIDA (1991) Comentarios al código civil y compilaciones forales, dir. Albadejo, t XVI- 1, Madrid, 1991. P 789, En contrario CAÑIZARES LASO (1996) ob. Cit; p 76 
realizado engrosado con las garantías que ostentaba el primer acreedor, de tal manera que quien paga y se subroga no persigue el crédito de otro, sino el propio junto con las garantías para su pago. Es decir las garantías primigenias, de tal manera que todas las garantías que protegían al crédito que se extinguió como consecuencia del pago protegen de la misma manera el crédito del subrogado. $\underline{\underline{3}}$

El efecto extintivo del pago se mantendría en todo caso y es en mi opinión la solución más acertada del efecto del pago por subrogación, lo que nos llevaría a afirmar sin duda alguna que el objetivo principal de la figura no es el de transmitir el crédito primigenio.

Esta ficción tendrá entonces la finalidad primordial de mantener frente a los terceros la misma posición que tenía la deuda primigenia pero por cuenta del interés en las garantías e hipotecas lo que nos lleva a preguntarnos ¿qué sucede con créditos no garantizados por hipoteca o finanzas o una garantía sobre el mismo como es el caso de la subrogación del asegurador en los derechos de subrogado? Lo autores mencionados estiman que el crédito nuevo ocupa el mismo lugar; y es que en eso consiste la subrogación. Quien paga debe de todos modos mantener la misma posición del acreedor primo, y es que la misma finalidad puede conseguirse sin que necesariamente sea el mismo crédito que se extingue. Este razonamiento lleva a concluir que en el tiempo, los créditos tiene dos momentos por un lado nace el crédito derivado de la relación primigenia entre acreedor y deudor como causa directa del acuerdo de voluntades o siniestro y posteriormente, con fundamento en el pago extintivo realizado al tercero nace uno nuevo sustituyéndose así el acreedor original.

En general entonces en cuanto al derecho de crédito, el ordenamiento establece la subrogación (art 1666 c.c.), supuesto que se extendería a

34 MARCADE (1873) Explication theorique et practique du Code Civil 7.a ed; t IV Paris, p.576, en el mismo sentido ANA CAÑIZARES LASO (1996) ob. Cit; p 55, Esta última a cita una serie de autores que entiende a la subrogación como mecanismo extintivo del crédito, que consecuentemente lleva al nacimiento de uno nuevo, su estudio se sitúa desde las instituciones del derecho romano hasta el moderno derecho francés entre otros autores: BETTI (1970) teoría general de las obligaciones t II. Por De los Mozos, Madrid P 253, MERLIN (1815) repertoire universal et raisonné de jurisprudence, 4 ed, t XIII, París, pp 21 y ss, LOYSEAU (1763) Du droit des officiés, París, 1,III, cap.8. Otros autores franceses como POHOTIER, LAURENT, GAUTHIER, MPOURLON, parten del efecto extintivo del pago entendiendo que existe una especie de cesión ficticia en la cual por un lado el subrogado ocupa el mismo lugar que el acreedor originario, y por el otro entre el subrogado y el acreedor hay un pago ordinario y puramente extintivo. 
toda forma de satisfacción del acreedor, como un efecto diferente del designio de las partes y del tercero con la finalidad de proteger el derecho del acreedor que paga, consideraciones de orden público y de seguridad jurídica, pero siempre con el objetivo de satisfacer a quien se convierte en acreedor, satisfacción que se considera por las normas como taxativa ${ }^{35}$. Cuando el pago no se hace por un deudor sino por un tercero (art 1630 c.c.), se supondría que sacaría de la relación jurídica al acreedor en todo o en parte en la medida a su satisfacción pero no extingue la obligación que por mandato de la ley subsiste y no en beneficio exclusivo del tercero que subentra, sino también en beneficio del acreedor primigenio, que puede intervenir o no cómo en el caso de la concurrencia de derechos. $\frac{36}{6}$ El razonamiento del privilegio de crédito entre acreedores caracterizados por darse entre ellos una relación previa (específicamente la que se da por el pago de un tercero con subrogación art 1212 C.C en concordancia en el caso de la fianza del artículo 1839 es la que se plasma en el 1213 C.C. de acuerdo al cual "el acreedor a quien se hubiere hecho un pago parcial puede ejercitar su derecho por el resto con preferencia al que se hubiera subrogado en su lugar a virtud del pago parcial del mismo crédito). Ello afirma la idea plasmada que en realidad existe un verdadero privilegio crediticio, no sobre un mismo crédito sino sobre créditos individualmente considerados frente a uno o varios acreedores, en un sentido subjetivo ya que se limita a fijar la prelación para el pago entre dos acreedores que en virtud de la subrogación parcial comparten la titularidad de créditos, con las garantías y causas de preferencia que corresponderán con el tiempo del nacimiento de los créditos. Esta forma de prelación no impide que pueda ser ejercitada tanto en el ámbito de una ejecución singular, o a través de la correspondiente tercería de mejor derecho, como puede ser un procedimiento concursal a pesar de la taxatividad que establece el artículo 89,1 LC.

35 CFR STS 8386/1993 - ECLI: ES:TS:1993:8386 Id Cendoj: 28079110011993101983 Órgano: Tribunal Supremo. Sala de lo Civil. Cas de 26 de febrero de 1894, XI,224. Cas de 26 de noviembre de 1935 , XLIII, 392 Y Sig.

36 Como se ha dicho se puede pensar de dos maneras, la historia de la de la doctrina nos trae dos alternativas en general por un lado la eficacia de la extinción de pago, o el tratar de justificar la no ocurrencia de la sucesión siendo una especie de sucesión ficticia, o extinción parcial, expropiación del crédito. A pesar de que como se había dicho la subrogación consiste en una verdadera sucesión del lado activo de la relación obligatoria es en realidad el nacimiento de una nueva como consecuencia y causa del pago lo que explicaría mejor la cuestión de las cotitularidades frente al tercero deudor: por un lado si existe un interés del acreedor primario y la obligación no está completamente extinta por existir efectos obligacionales la obligación de ninguna forma estaría fictamente extinta, por otro lado en consonancia con lo expuesto hasta ahora el derecho que nace del pago por parte del tercero que paga es una obligación para el nueva. 
Pero no es el único caso de preferencia que establece la L.C. (Ley concursal), a lo largo del texto se encuentra diferentes supuestos que revisten la misma lógica, $\frac{37}{}$ es claro que la razón de ser de los privilegios en estos casos van en desmedro de terceros como sucede en el régimen general del pago por subrogación; y por estar consagrado legislativamente la voluntad de las partes no puede otorgar carácter de privilegio a un determinado crédito, y mucho menos modalizar o alterar el contenido de los privilegios establecidos por la ley. La autonomía privada solo puede disponer aquellas situaciones jurídicas que la ley otorga la posibilidad de ser preferentes, lo que otorga su carácter prescriptivo y una tipicidad inalterable. ${ }^{38}$ Siendo de origen legal su consagración se encuentra en el 1925 C.C el cual determina "que no gozará de preferencia los créditos de cualquier otra clase o por cualquier otro título no comprendidos en los artículos anteriores" y la ley concursal establece por su parte en el artículo 98,2 que "no se admitirá en el concurso ningún privilegio o preferencia que no esté reconocido en esta Ley."

Es claro que la literalidad de la norma en el contrato de seguro nos describe un tipo de subrogación legal; y es sin duda alguna reconocida por la mayoría de la doctrina y la jurisprudencia ${ }^{\underline{39}} \mathrm{Y}$ sin necesidad de

37 DÍEZ SOTO CARLOS MANUEL (2006) Concurrencia y prelación de créditos teoría general, DIAZBASTIEN \& TRUAN (2006) pág. 38, Madrid, como ejemplos el autor cita el artículo 160 y 161,3 en relación con el arti 87,7 los cuales afirman la preferencia del acreedor parcialmente satisfecho sobre le fiador avalista o deudor solidario que hubiere realizado el pago parcial del crédito. También el artículo 87.6, que en caso de pago parcial por le fiador ordena optar por la calificación menos gravosa para el concurso entre las que correspondan al crédito original del acreedor y al fiador en cuanto al reembolso. Se debe tener en cuenta que a pesar de la interpretación literal que se puede hacer del segundo inciso del artículo 87.6, el artículo 87.7 LC propende por no perjudicar perjudicado el acreedor que obtuvo el pago parcial del tercero. En este mismo sentido cfr. CORDERO LOBATO, E (2004) Comentarios a la Ley Concursal (coord. por Bercovitz Rodríguez-Cano, R.), p. 1036; MERCADAL VIDAL (2004) F., Nueva Ley Concursal (coord. por Sala, A./Mercadal, F./Cuevillas, A.), p. 437. 26.Barcelona

38 GARRIDO, JM (1954) Teoría General de la preferencia, en ADC, OCT-DICIEMBRE. 1998 PP 1776, 1784,1785 Y 1822, 1823.

39 TATO PLAZA (2004) la subrogación del asegurador en la ley de contrato de seguro, ed Tirant lo Blanch, 2002, pág. 58, SÁNCHEZ CALERO (1999) ley de contrato de seguro, pág. 655, en la doctrina italiana FIORENTINO, L'assicurazione, pág. 133, Tribunal Supremo. Sala de lo Civil, Roj: STS 6633/2013, 19/11/2013; en esta sentencia el tribunal supremo esgrime una serie de argumentos y efectos a entender encaminados a que la subrogación en seguros es una de las formas de subrogación legal ; reitera que La doctrina en general centra el fundamento de la subrogación legal del asegurador sobre las siguientes bases. Primero, el evitar que el asegurado que, como consecuencia del siniestro, tiene una doble vía de resarcimiento del daño (contra el asegurador y contra el causante del daño), pueda enriquecerse ejercitando ambos derechos (el principio indemnizatorio a que se refiere el art. 26 LCS ); segundo, impedir que el tercero responsable se vea libre de su obligación de resarcir el daño por la protección que obtiene el asegurado merced al contrato de seguro; tercero, el suponer que es un beneficio para el asegurador, pero también para el asegurado en la medida en que el primero obtiene unos recursos que le favorecen una mejor explotación del negocio y el segundo no verá incrementada 
hacer distinciones profundas las tesis alternativas a su naturaleza no son correctas al interpretar y darle alcance diferente al artículo 43 LCS. En efecto algunos doctrinantes han explicado la figura como una cesión de créditos argumentando que lo consagrado en el mencionado artículo mirándolo de forma detallada se estaría en presencia de una cesión de carácter legal en favor del asegurador del crédito que ostentaba el asegurado frente al tercero responsable ${ }^{40}$; sin embargo estas tesis se enfrentan a un inconveniente en el sistema jurídico español en cuanto a que en la cesión legal el legislador español la ha consagrado de forma expresa. En efecto el articulo 1778 C.C el heredero del depositario que de buena fe haya vendido la cosa que ignoraba ser depositada - dice este precepto que solo está obligado a restituir el precio que hubiere recibido o a ceder sus acciones contra el comprador en el caso de que el precio no se le haya pagado. ${ }^{41}$ Por otro lado es claro que la cesión de créditos tiene carácter especulativo ${ }^{42}$, teniendo en cuenta que a pesar de negar tal condición en el contrato de seguro; entendiéndola como una acción de recobro no se puede desconocer su carácter especulativo por el hecho de que existen

la prima que, en caso de insolvencia del responsable del daño, debiera soportar. Las razones apuntadas ya aparecían en la exposición de motivos del Código de Comercio de 1885: "Satisfecho el asegurado de cualquiera de los modos indicados, es de estricta justicia que, como consecuencia de este acto, quede subrogado ipso iure el asegurador en todos los derechos del asegurado, contra los terceros que sean responsables, por cualquier título o concepto; pues ni el asegurado, una vez percibida la indemnización, puede exigir de éstos otra, lo cual constituiría un lucro o beneficio, en oposición con la naturaleza fundamental del mismo contrato, ni los terceros quedan libres de su responsabilidad en virtud del seguro, como acto ajeno a ellos, siendo, por el contrario, muy ventajosa esta subrogación al mismo asegurado, que obtendrá por ella alguna rebaja en la cuantía del premio del seguro “. II.Naturaleza jurídica de la subrogación. Aunque se sostiene por algunos que la subrogación constituye una cesión de créditos, o un supuesto atípico de sucesión en el crédito del asegurado frente al tercero responsable, o un supuesto particular de subrogación por pago, es lo cierto que el art. 43 LCS establece una subrogación legal -aunque no se produzca automáticamente; Procede la jurisprudencia reiterando la tendencia doctrinal, que mientras la cesión, es el cauce para realizar el interés de la circulación del crédito, la subrogación atiende a la satisfacción de un interés subrogado para recuperar, por vía de regreso, un desembolso patrimonial efectuado por el asegurador. En el mismo sentido sobre la naturaleza legal de la subrogación en el contrato de seguro: Tribunal Supremo. Sala de lo Civil Roj: STS 2154/2010 del 30/03/2010, Tribunal Supremo. Sala de lo Civil Roj: STS 2183/2006; del 23/03/2006; entre otras. Se caracterizan estas sentencias por ser incisivas en el sentido que la subrogación es un mandato legal prescriptivo.

40 BENITEZ DE LUGO REYMUNDO (1955) Luis: “Tratado de Seguros". Vol. II: "Los seguros de daños"; Instituto Editorial Reus. Madrid, 1955, p 255,

41 TATO PLAZA (2002) la subrogación del asegurador en la ley de contrato de seguro, ed Tirant lo Blanch, 2002, pág. 59

42 TATO PLAZA (2002) la subrogación, refiriéndose a la doctrina en este sentido, RUIS SORA, JOSE MARÍA, la subrogación del asegurador. Especial referencia al seguro marítimo, Tesis Doctoral inédita, San Sebastian, 1975, p 143. En la doctrina italiana, DURANTE, Aldo, L assicurazione di responsabilitá civile, Giuffré, Milan, 1959. P 228; LA TORRE Antonio, il punto sulla surrogazione dell' assicuratore, Ass 1978-I, P 351. En la doctrina Francesa LAMBERT - FAIVRE Ivonne, Droit des assurances, décima edición, Dalloz, París, 1998, p 402. 
los principios de cálculo de probabilidad y previsión de lo imprevisible como se explicó con anterioridad.

Y refiriéndose a la cesión consensual es claro que el objeto de la cesión de créditos es la titularidad activa de la relación obligatoria simple $\mathrm{y}$, en principio, el consentimiento es bilateral. Se ha definido la cesión de crédito como aquella convención por la cual el acreedor (cedente) transmite a otra persona (cesionario) su derecho contra el deudor lo cual implica que el acto que genera la figura tiene efecto hacia el tercero cedido sin que este deba manifestar su voluntad. Para que tenga validez solamente será necesaria la notificación que se le haga del negocio de cesión al cedido.

Dicha sustitución se realiza mediante un acuerdo de voluntades que se fundamenta en la ejecución de una serie de contratos de diversa naturaleza, los cuales tienen como objeto derechos crediticios (compraventa, donación, dación etc) En el primer inciso del artículo $2^{\mathrm{a}}$ de la Convención de las Naciones Unidas sobre la cesión de crédito en el comercio internacional, firmada en Nueva York en 2004 (Convención CENUDMI), establece; que por "cesión se entenderá la transferencia consensual por una persona (cedente, a otra (cesionario) de la totalidad, de una fracción o de una parte indivisa del derecho contractual del cedente a percibir una suma de dinero (crédito) de un tercero (deudor)"

En el caso de la subrogación en seguros la causa no es el interés en los derecho crediticios sino el recupero de una cantidad dada al asegurador como consecuencia de una eventualidad, dicha eventualidad es inexistente en el contrato de cesión, el objeto principal de la misma es la cesión para asegurar en las prerrogativas del cedente frente al cedido.

Así mismo puede darse el caso de la cesión parcial como lo habla la mencionada convención es decir de solo una parte del mismo, siempre que la prestación objeto del mismo sea divisible y la cesión parcial no este excluida por pacto con el deudor; en relación con la tendencia a que en las cesiones las relaciones obligatorias en su parte acreedora sean modificativas el código civil dispone en el artículo 1112 "Todos los derechos adquiridos en virtud de una obligación son transmisibles con sujeción a las leyes, si no se hubiese pactado lo contrario. Es lógico entonces que la 
facultad exigendi en que consiste la parte activa de la obligación puede realizarse a otro sujeto salvo pacto en contrario; pacto que podrá negar las cesiones parciales o permitirlas en determinadas condiciones, Así es establecido por la ley hipotecaria, Artículo $149 \mathrm{LH}$, sin que la doctrina desapruebe su aplicabilidad a la cesión de otra índole, es esta la posición dominante en el derecho comparado ${ }^{43}$. En nuestra jurisprudencia con respecto a las cesiones parciales o no extinguidas, podemos hallar algunos pronunciamientos generales en donde se denota su naturaleza negocial, relacionando la figura con una simple compraventa de créditos especial, caracterizada por su contenido de cosas incorporales que se diferencia de la compraventa ordinaria en la entrega y el saneamiento de lo que se cede y de lo que se vende, y de todos modos será una nota diferencial entre los dos contratos la consideración que la venta consumada crea una relación directa entre el comprador y la cosa corporal adquirida, mientras que en la cesión de créditos no se trasmite cosa alguna sino el título o derecho de reclamarla a una tercera persona. Así mismo se hace énfasis en que la cesión de crédito es un negocio directamente bilateral en el cual el acreedor - cedente transfiere por pactos intervivos la titularidad de su crédito a un tercero (cesionario) con lo cual el crédito circula. Ratificando además la idea que el crédito es el mismo y lo que cambia o supone un cambio de acreedor siguiendo incólume la relación jurídica inicial. ${ }^{44}$ Es el efecto de la cesión parcial la división del crédito original, en una pluralidad de créditos, tal como lo vimos en la subrogación parcial, cada uno de ellos seguirá su propia suerte de acuerdo a las reglas de los créditos parciarios y de igualdad, pero que se diferencia en que quien primero exija el crédito se preferirá, no existiendo prelación alguna, es decir de quien cede o a quien se cede, siendo la temporalidad en el nacimiento de los derechos de crédito frente al cedido irrelevantes; quien determina tal sucesión es el deudor que podrá determina a quien paga o a quienes les paga en el orden que este prefiera, lo que no implicaría que los acreedores (cedentes cesionario o cesionarios) le exijan al cedido en un orden especifico su derecho de crédito.

43 PANUCCIO (1955) la cessione volontaria dei crediti nella teoría del transferimento , Cessione dei crediti, Enci del dir VI. DERDELER TEILZESSION UN SCHULDNERRECHTE (1969), en comentario del códice CIVILE SCIALOJA-BRANCA. PERLIGERI, Della cessione dei crediti (1982), en comentario del códice civile SCIALOJA BRANCA, RIEG (1985).

44 STS 12 de noviembre de 1992, sts 1 de julio de 1949, STS 17 de diciembre de 1994, STS 26 de septiembre de 2002 . 
Podría también por pacto que el cedente o cedentes con relación al cesionario o cesionarios asignar un orden especifico de prelación, este pacto tendrá en todo caso el efecto relativos de los contrato es decir entre ellos no siendo oponible tales acuerdos al deudor, salvo que este haya sido notificado de tal prelación, cuestión que por la esencia misma de las cesiones por la parte activa solo es necesaria la mencionada notificación sin que el deudor se pueda oponer a ello.

\section{BIBLIOGRAFÍA}

BENITEZ DE LUGO REYMUNDO (1955), Luis: “Tratado de Seguros”. Vol. II: "Los seguros de daños"; Instituto Editorial Reus. Madrid, 1955, pág. 255.

CALZADA CONDE M, A (2008), la subrogación del asegurador y la protección de los intereses de los asegurados en RDM, N 270

CAÑIZARES LASO ANA (1996), el pago con subrogación, ed, Civiltas. Madrid.

CORDERO LOBATO, E (2004), Comentarios a la Ley Concursal (coord. por Bercovitz Rodríguez-Cano, R.), p. 1036; Mercadal Vidal, F., Nueva Ley Concursal (coord. por Sala, A./Mercadal, F./Cuevillas, A.), p. 437. 26.

CORRALES ELIZONDO AGUSTÍN (1982) La regla proporcional y la Ley de Contrato de Seguro Colegio Universitario de Estudios Financieros, CUNEF.

DÍAZ MORENO, Alberto (2008): La disciplina de la póliza estimada en la Ley de Contrato de Seguro, Cuadernos Civitas, Thomson Civitas, Madrid, $1^{\text {a }}$. Edición.

DÍEZ PICAZO Y PONCE DE LEÓN (2011) Fundamentos del derecho civil patrimonial, Vol V 1 ed, Aranzadi, Pamplona.

DÍEZ SOTO CARLOS MANUEL Concurrencia y prelación de créditos teoría general,

DIAZ-BASTIEN \& TRUAN (2006) pág. 38 Madrid 2006. 
DURANTE ALDO, L (1959) assicurazione di responsabilitá civile, Giuffré, Milan, 1959. Pag 228;

FERNANDO SÁNCHEZ CALERO. (1999) Ley de contrato de seguro. Aranzadi, Pamplona, pág. 652.

GARCÍA GOYENA (1974) Concordancia motivos y comentarios del Código civil español, Ed Lacruz Berdejo, Zaragoza., 1974.

GARRIDO Y COMAS (1954) Tratado general de seguros, Teoría y práctica de los seguros privados, T. I, Teoría general y Derecho español de seguros, Vol. I, p. 119.

GARRIGUES (1973) contrato de seguro terrestre, p.202. 107 y ss.

GILMORE, GRANT BLACK, Charles L. Jr. (1957) Law of Admiralty, The Foundation Press, Inc. Brooklyn, P 81

IVONE LAMBERT FAIVRE (1990) Droit des Assurances, Dalloz, París, pág. 336.

LA TORRE Antonio (1978) il punto sulla surrogazione dell' assicuratore, Ass, pag 351.

LAMBERT - FAIVRE Ivonne, (1998) Droit des assurances, décima edición, Dalloz, París, pág. 402.

M.A. Clarke (2009) the low of insurance contracts, 6 ed; Londres, pag 1028 ,

MAZEUD- MAZEUD-CHABAS (1991) Lecons de Droit Civil, II, Paris, pp 954 y ss.pp. 609-610 y 619.

MERCADAL VIDAL (2004) F., Nueva Ley Concursal (coord. por Sala, A./ Mercadal, F./Cuevillas, A.), p. 437. 26.

RIGHETTI, G, (1994) Trattato di Diritto Maritimo, Milano, Pág. 628. 
RUIZ SÁNCHEZ (1988) José Luis: «Las reglas proporcional y de equidad y el contrato de seguro», en Revista Española de Seguros, AIDA -Sección Española, Editorial Española de Seguros, S. A., nº. 55, julio/septiembre, p. 101.

RUIZ SOROA, J.M (1984) fundamentos de la subrogación legal del asegurador, en ADM, vol II, 1984, p 347,

SÁNCHEZ CALERO (1999) ley de contrato de seguro. Comentario al a ley 50 /1980, de 8 de octubre, y a sus modificaciones, Aranzadi, Pamplona pág. 664.

SANCHO REBULLIDA (1991) Comentarios al código civil y compilaciones forales, dir. Albadejo, t XVI- 1, Madrid, PAG 789

SOTO ABELEDO JAVIER (2011) La regulación del infraseguro, la regla proporcional y la póliza estimada en la ley de contrato de seguro y en el seguro marítimo. COLECCIÓN DE DERECHO MARÍTIMO

TATO PLAZA (2002) la subrogación del asegurador en la ley de contrato de seguro,V RUIZ SOROA, J.M (1975) la subrogación de asegurador. Especial referencia al seguro marítimo, tesis doctoral inédita, san sebastián pag 347.

VERDERA, TUELLS y OTROS (1982) Comentarios a la Ley de Contrato de Seguro, Vol. I, pp. 597-627 Colegio Universitario de Estudios Financieros, CUNEF

WALTER VILLA ZAPATA (1997) La subrogación en el derecho de seguros peruano. En: Revista Ibero-Latinoamericana de Seguros. No X, Bogotá, pág. 151

\section{Jurisprudencia}

STS de 3 de abril de 2007, STS de 241/2009, de 20 de abril, STS de 13 de febrero de 1988, STS, 24.1.2002, STS 13.2.2001, STS 17.10.1998, STS 5.2.1998, STS 2013/2011 STS 2013/2011, STS 8386/1993, STS 8386/1993, STS: 1993:8386. 
Sentencia audiencia provincial de Barcelona de 7 de septiembre de 1998. Sentencia de la audiencia provincial de Madrid de 15 de julio de 1998.

Proceso arbitral “Ana Undurraga Laso c/Cía. La previsora y la Chilena consolidada; árbitro Superintendencia de Valores y Seguros; 12/02/1938. 